\title{
Writing Across the Curriculum Encounters Asynchronous Learning Networks or WAC Meets Up With ALN
}

\author{
Gail E. Hawisher \\ Michael A. Pemberton \\ Department of English \\ University of Illinois, Urbana-Champaign \\ email: hawisher@uiuc.edu \\ email: michaelp@uiuc.edu
}

\begin{abstract}
This paper illustrates some of the problems and successes that the authors encountered while integrating ALN into a writing across the curriculum program and an online writing lab at a large research university. Using transcripts from ALN class discussions, the authors examine students' networked interactions and analyze the classes' responses to a variety of online assignments in a class on English composition and pedagogy, a course on electrical and computing engineering, and a class on writing technologies. In so doing, the authors set forth several pedagogical principles which emerged from their experiences with ALN in their individual classes but which also share a number of commonalities with effective WAC practices.
\end{abstract}

\author{
KEYWORDS \\ computer networks \\ computers and composition \\ online writing labs \\ online forums \\ electronic conferences \\ teaching of writing
}

\section{INTRODUCTION}

The Writing Across the Curriculum (WAC) movement has been a powerful force for change in American higher education. In the twenty years since Barbara Walvoord first established a WAC program at Central College in Pella, Iowa[1], and Art Young and Toby Fulwiler introduced such a program at Michigan Technological University[2], the movement has made its mark on the country's institutions of higher learning. At colleges and universities where there are WAC programs, faculty often assign more writing, are likely to become more involved in their students' learning, and often change their pedagogical approaches to more interactive and participatory modes with students writing frequently in response to their instructors and classmates. WAC instructors, moreover, often assign different kinds of writing-assignments which are shorter but completed more frequently, assignments targeted at audiences other than the instructor, and assignments which have the explicit aim of helping students learn the subject matter of the course. In such writing-to-learn WAC classes, faculty also tend to lecture less and to encourage students to participate more, often viewing the classroom as a space where teachers and students come together to engage in exciting intellectual activity[3]. 
But if the spread of WAC throughout the nation's colleges and universities has been significant, and we think it has, the increased use of computer-mediated communication or what our campus calls asynchronous learning networks (ALN) has been extraordinary. In ten short years, the use of computer networks in the service of learning and the teaching of writing has become commonplace[4], and one need only glance at the weekly Chronicle of Higher Education to note the plethora of articles that promote ALN. Those of us who have worked with computer networks recognize their promise, but we also realize that computer networks can be used to support teaching approaches every bit as ill-considered as those found in some traditional correspondence courses where instructors send out course materials to students who are then expected to absorb the material and send back answers to prescribed questions, with little interaction occurring between the instructor and students. What is often lacking in these computer-supported network approaches are the critical exchanges taking place not only between the instructor and students but also among the students themselves - the kinds of reciprocal exchanges made possible through ALN. This sort of critical ongoing dialogue is also a hallmark of WAC classes in which teachers and students come together as learners-in-progress, collaborating and interacting in such a way that they form new communities of learning. In our minds, the twenty-year-old WAC movement has much to teach those of us who use computer networks for teaching, those of us, if you will, who use ALN[5]. We use the term ALN to distinguish it from everyday networked discourse or from the computer-mediated communication that we engage in through e-mail or professional listservs. ALN, in other words, denotes online class activities that have the explicit function of promoting learning and thus corresponds more closely to the profession's notion of WAC contexts. Both WAC and ALN are capable of reshaping the social contexts of classes if we bring to them the necessary kinds of critical thinking and pedagogical values that successful educational innovations require.

In this paper, then, we would like to offer our experiences as a basis for what we can and cannot expect when WAC and ALN come together. We first describe the beginnings of an online WAC program at the University of Illinois and describe how teachers used ALN in their classes. In describing our own experiences, we set forth several pedagogical principles which emerged from our work and which apply to our own teaching in online conferences. Following our discussion of online WAC contexts, we then turn to a description of how we experimented with ALN in the Writers' Workshop, the university's tutorial facility, and of how we were unable to attract sufficient student participation to allow us to experiment more fruitfully with online consultations. We end with a few broad-based suggestions that have come to guide our own use of electronic networks in writing-intensive courses.

\section{A. Historical Background and Context}

The Sloan Foundation awarded the University of Illinois a sizable grant in early 1995 to experiment with ALN. There were a great many articles in the popular press touting the promise of the Internet as a provider of "distance learning," and there was much talk about the possibility of American universities offering degrees earned primarily in virtual contexts (e.g., Honan, Blumenstyk)[6]. From the start, however, the Sloan grant at the University of Illinois was conceived of as what the Sloan Foundation calls "on or near-campus" learning. In awarding the grant, Frank Mayadas of the Sloan Foundation stated,

It is most natural to associate the ALN concept with distributed classes of off-campus learners. However, it is also worthwhile to explore benefits and outcomes from such networks implemented for traditional on-campus students. While most of the communication on campus is face-to-face, the special benefits of asynchronous problem- 
solving collaboration, assistance from teaching assistants and faculty, and other kinds of networked access need to be explored, and are of interest to us (Mayadas)[7].

Thus, in 1995, the Center for Writing Studies began extending its earlier experiments with ALN into classes that were part of its writing across the curriculum program. At the University of Illinois, WAC is one of the three programs which comprises the Center for Writing Studies. The Center was established in 1990 to improve undergraduate education through WAC and the drop-in tutorial facility which was also created at this time and which we subsequently named the Writers' Workshop. Undergirding the two undergraduate emphases is a cross-disciplinary graduate program which we argued would provide committed faculty and intellectually engaged teaching assistants to work in the Center programs. Part of the mission of the WAC program was to support a second writing course, Composition II, but from the start we construed our mission as encompassing more than the support of a second writing requirement. We argued that if WAC practices are introduced to all faculty who are interested and who attend the four-day WAC seminars for which they receive a stipend, the WAC culture will begin to change the way teaching is carried out across the university. Because the university is one of the nation's largest research universities, this was no small challenge, but over the years more than 250 faculty members have attended our seminars and have also come back to the yearly seminar to demonstrate for their colleagues their own WAC practices. In the time we have worked to establish the Center and its programs, we have been gratified to see evidence of small, incremental changes in teaching practices at the university which we believe are making a difference in the way students learn. In research Hawisher and her colleagues have conducted, instructors report that in many cases they have replaced the obligatory "term paper" with frequent, shorter writings throughout the semester and that the change has resulted in what they perceive as increased student learning[8]. The introduction of ALN became yet another way in which we could work with faculty members and teaching assistants to improve pedagogy across the university.

Thus, in the proposal to Sloan, we had written that ALN would be incorporated into selected classes participating in the University's WAC programs, all taught by several faculty we recruited from five years of WAC seminars. Using the commercial packages of PacerForum and FirstClass[9] (see Figures 1 and 2.), faculty teaching courses in Art Education, Classics, Comparative Literature, Economics, Electrical and Computer Engineering, English, Film, and Urban Planning adopted ALN in one or more or their classes and experimented with different kinds of assignments, all using the online environment as a supplement to face-to-face discussions. In addition to setting up discussions for students, we also created a space where faculty could discuss with one another their experiences using WAC and ALN, an e-space which functioned similarly to the international listservs of WAC-L and CCAC-L but which included only faculty teaching in the program. (See Figure 3. for an example of a faculty exchange.) The Center also hired two additional teaching assistants, one from engineering and the other from communications, both of whom were funded through Sloan and primarily worked with the Writers' Workshop. (In Figure 4. Pemberton introduces the engineering TA, Bevan Das, and the Writers' Workshop to any student in the WAC classes who has signed onto PacerForum.) In what follows, we focus on our own experiences in using learning networks, along with those of one of our engineering colleagues, Burks Oakley. We try to examine more closely the reasons for our successes and failures in online teaching, all of which reflect the kinds of thinking that we also encountered in discussions with other WAC faculty. Our experiences—and conclusions—resonate closely with theirs. 


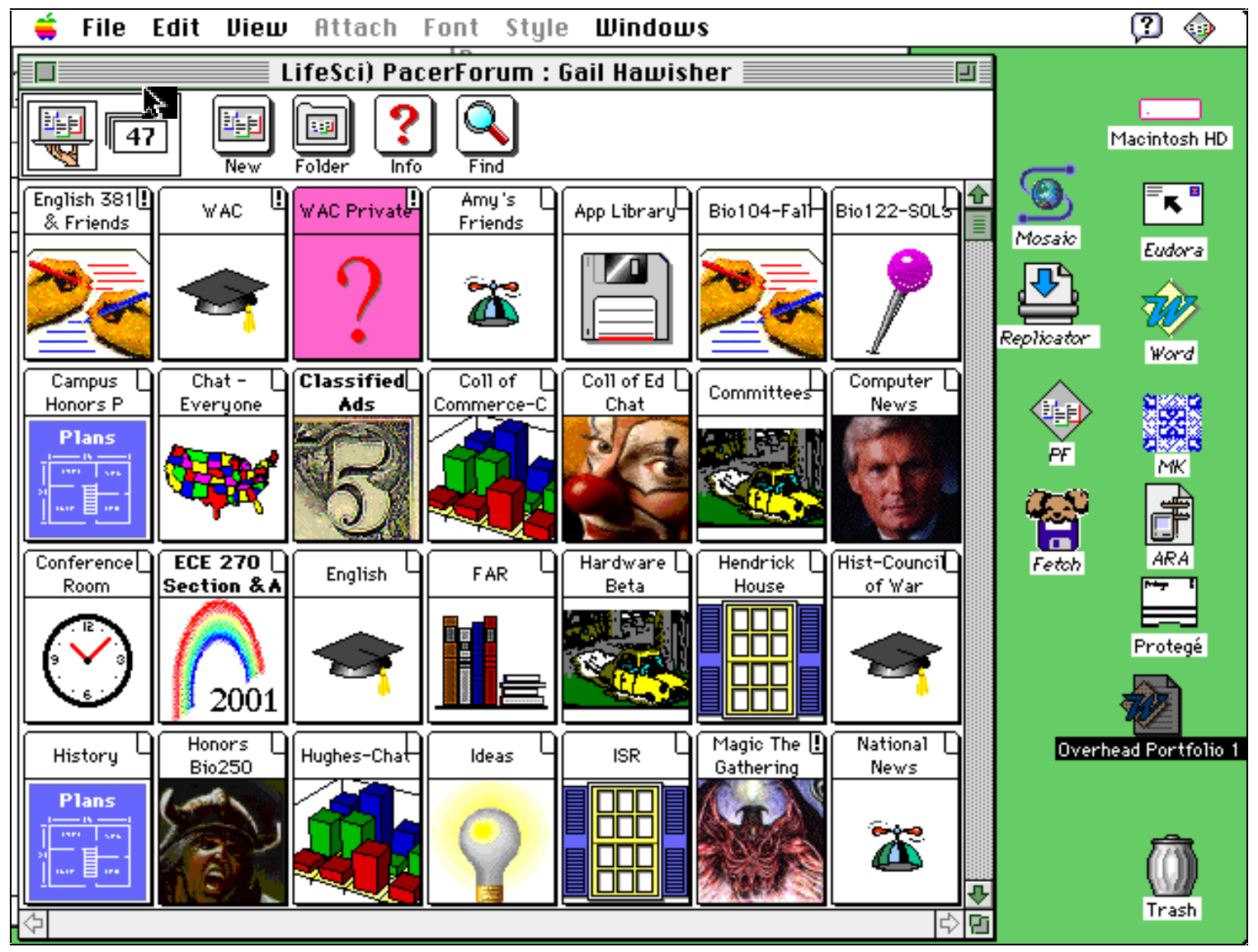

Figure 1. PacerForum Interface

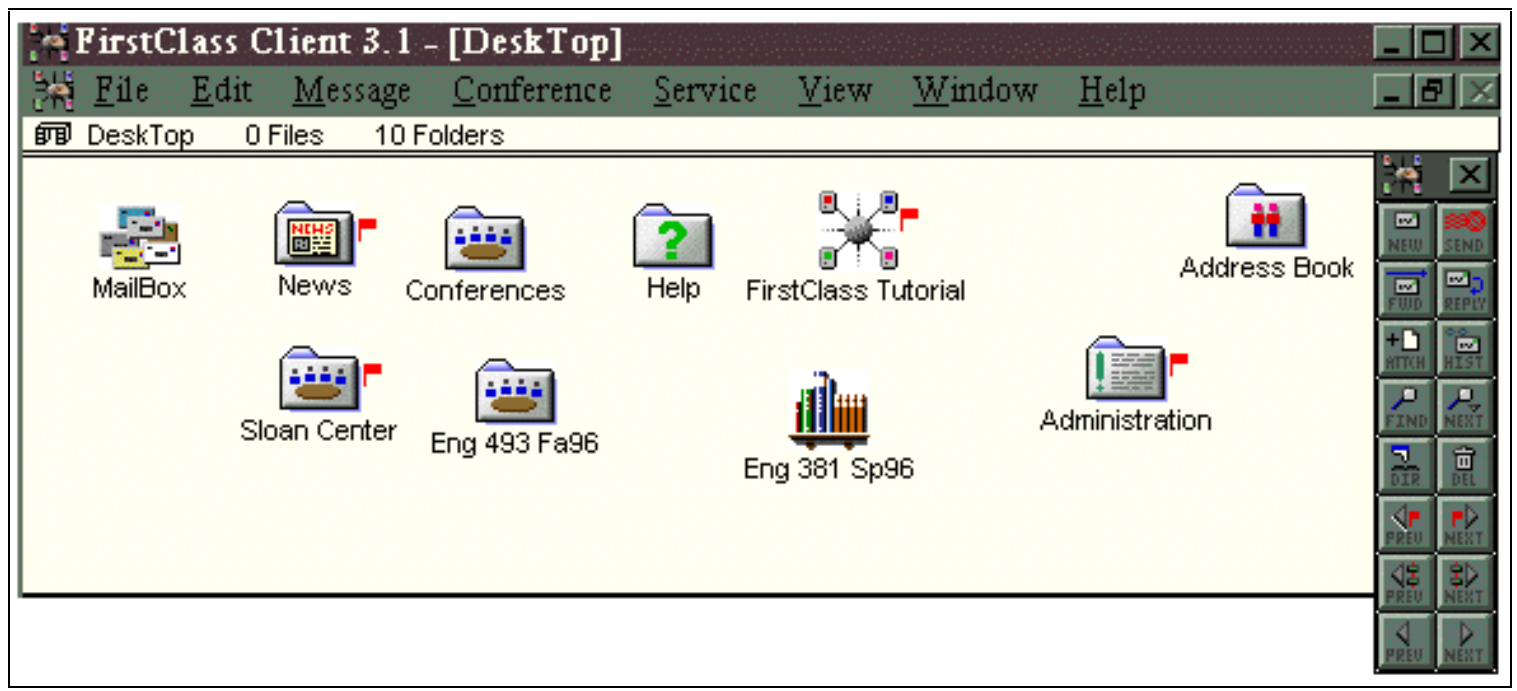

Figure 2. FirstClass Client 


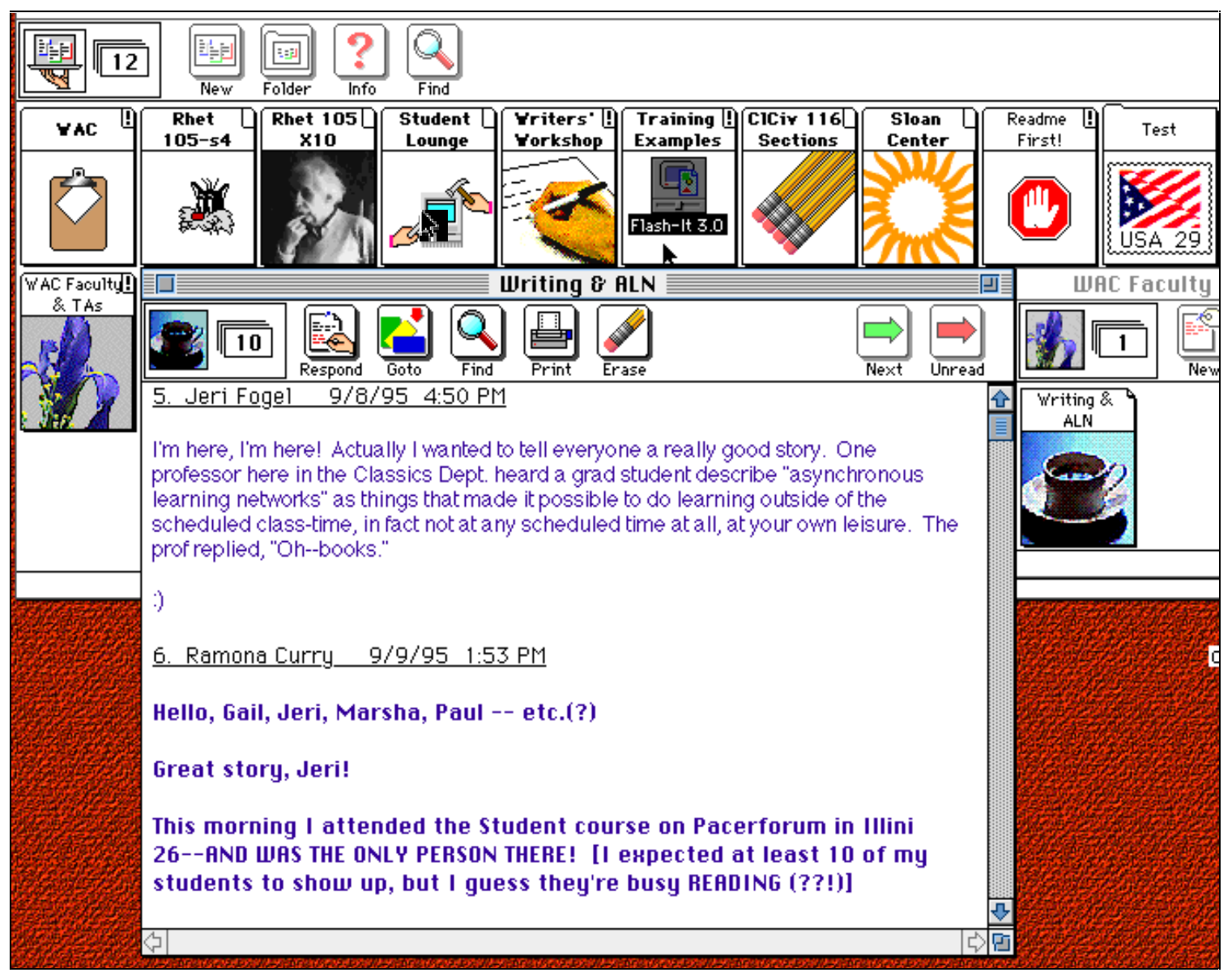

Figure 3. Faculty Exchange on PacerForum 


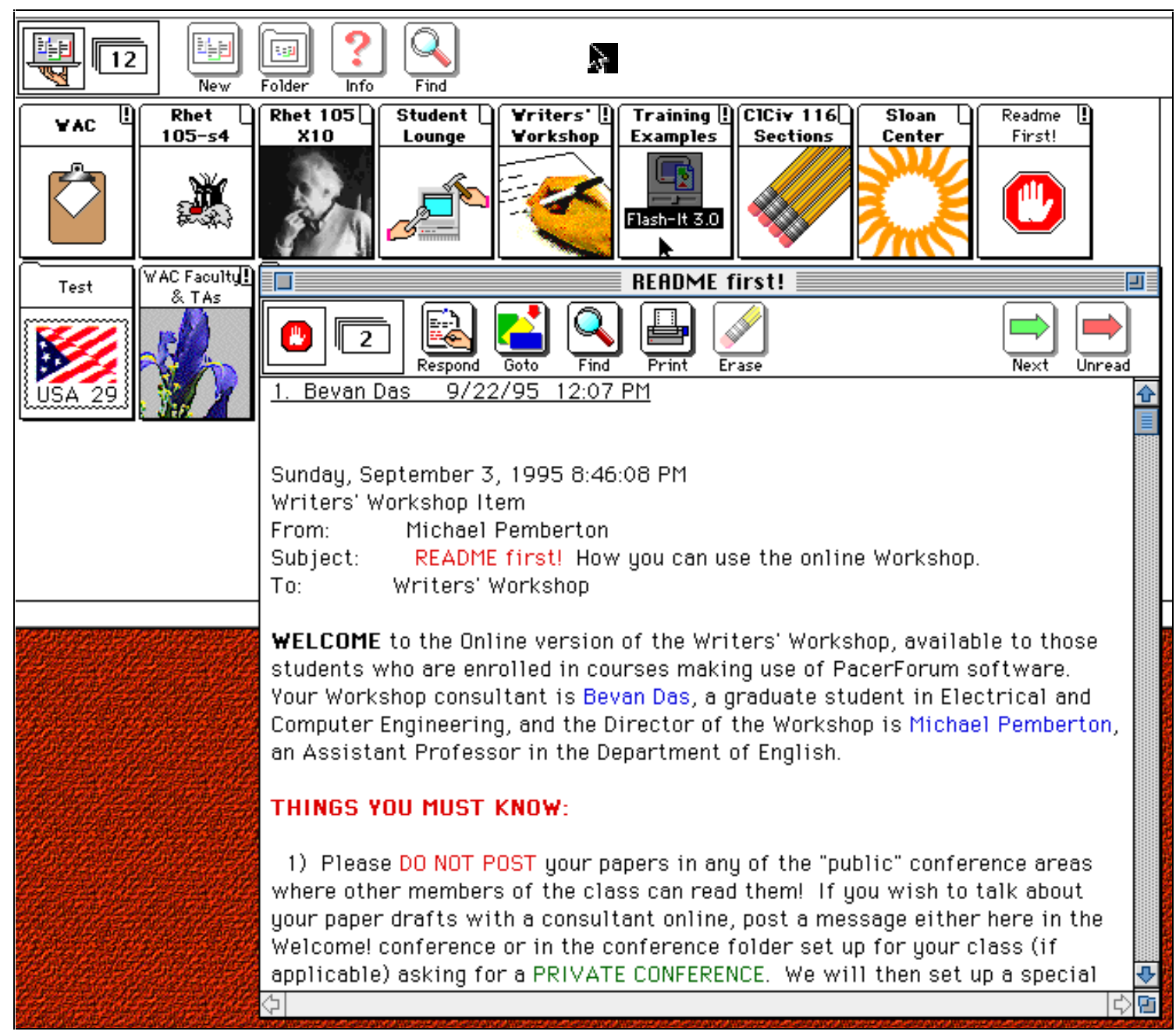

Figure 4. Writers' Workshop Introduction

\section{ALN AND WAC}

The use of ALN requires careful planning and sensitivity to the dynamics of online interaction in an academic environment. One of the authors of this paper, Gail Hawisher, had team taught a class several years before in which she and her co-teacher had asked students to post on the class's e-mail discussion list summaries of their weekly responses to the readings. Although the two instructors envisioned lively discussions growing out of the postings, predictably such discussions didn't occur. In retrospect, it is a mystery why the instructors should ever have expected animated online conversation over the readings when we consider the assignment they gave. All they had required of students were the postings of summaries of their more extended print responses, an activity that understandably led to little conversation. In fact, the posting and subsequent reading of seventeen weekly summaries became an exceedingly tedious activity for instructors and students alike.

An examination of the instructors' goals and assumptions seems to reveal that the two teachers expected from the e-mail class discussions the sorts of encounters common to lists where 100 or 
more people are participating (and not posting summaries we might add). The teachers automatically expected the characteristics, say, of personal e-mail and listservs to take hold in a class discussion of some seventeen students. What we learned from this experience was that even when postings were not graded per se, the tendency for students was to see their work as occurring in an educational context and therefore subject to evaluation. Regardless of how informal and supportive teachers expected these spaces to be, students still saw (and continue to see) their participation as required and graded.

Over the years Hawisher and her colleagues have tried to develop different online assignment strategies which they shared with the WAC instructors. Some of the strategies turned out to be more successful than others, with the effectiveness of the assignment depending ultimately on a particular instructor's goals for the online interaction. A few instructors tried to involve students by responding conscientiously to each of their postings while others wanted the e-spaces to be exciting intellectual centers inhabited primarily by students (Hawisher and Selfe).

\section{A. ALN in English 381}

The second author of this paper, Michael Pemberton, used FirstClass in his course on the Theory and Practice of Written Composition throughout the Spring 1995 semester. The course is primarily aimed at students majoring in the teaching of English and is largely made up of students in their junior year with a few sophomores, seniors, and graduate students in the course as well. In an effort to address some of the problems faced by other WAC instructors who had used ALN in their courses, Pemberton worked to meet three specific goals as he introduced the FirstClass software to the students in the class. First, he made sure that students were well-trained to use the software and felt comfortable with it early in the term. Second, he made students accountable for posting on a regular basis, requiring them at first to post messages twice a week on two separate days, then modifying that requirement to a minimum of two postings a week on whatever day or days they chose. The experiences of other instructors-and his own earlier unsuccessful use of class newsgroups - had demonstrated rather convincingly that teacher encouragement alone would not ensure regular student participation in ALN discussion groups[10]. In his course, therefore, students were told that their postings would be tallied each week and that their contributions on FirstClass would play a heavy role in the $15 \%$ of their final grade that depended upon "participation." Though students at first resented the twice-a-week rule, most of them slipped quickly into a routine that enabled them to meet this requirement with little difficulty. Third, Pemberton tried to integrate ALN into the course in ways that seemed natural to ALN, the FirstClass software package, and the goals of the course. When he violated this general guideline for one of the course assignments, the result was spectacularly underwhelming (as will be explained below).

For his course, ALN was used, first of all, to provide a forum to discuss issues central to the focus of the course but which could not be covered in the fullest measure in regular one-hour class meetings. A special "discussion area" was created with a wide assortment of possible topics related to writing instruction that students could contribute to. These topics included "Dealing with Dialect," "What About Grammar?" "Personal Stories," "History," "Writing Theory," "Multiculturalism," "Computers and Writing," and "School Administrations." Some of the online discussions became quite active, averaging eight to ten posts a day at some points, and some students frequently posted half a dozen messages or so each time they sat down at a computer, depending on how strongly they felt about the issues classmates were confronting. Two women who rarely said much in in-class discussions were among the most "vocal," contributing close to a hundred messages apiece during the course of the semester. Some of the topics provoked quite 
animated discussions, notably on the issues of multiculturalism and teacher responses to writing. The following two unedited posts by students in the course were typical of such discussions[11]:

Michelle

I believe we do not have the right to say on the student's paper (I don't care how bigoted it is) "what about the bill of rights?" We can, however, say "Have you considered how to answer people who would argue that your opinions do not stand up against the bill of rights?" You see, the first tactic implies that the teacher is ARGUING with the student's POSITION while she is EVALUATING the student's work. Let me repeat-- this is unethical! And, students will develop an unhealthy fear of stating their opinions in their papers for fear of retribution from you, the teacher.... As teachers, we must evaluate the student's work apart from our own biases. Then we can, if we want, discuss opinions in class or on a separate peace of paper. If I could simply grade students depending upon how close they come to my opinions when they write then hey, I could flunk anyone in the class that doesn't agree with me. Then what have you got? You've got a group of students who aren't really learning to think and argue for themselves. Rather, they are learning only to spout back the opinions that you give them....

Let me clarify something--- I did not agree with the student's opinions in the paper we read today. But, I did make a serious effort to dissociate my evaluation of the piece from my personal views on the issues discussed. I was alarmed at many other people who didn't seem as willing to do so. Forgive me if my language is harsh here, but I simply cannot stand by when I think some are going to make as grave an error as I am seeing them make. Folks, no matter how bigoted or ludicrous the opinion, you cannot punish a student for thinking differently. It's a fact of life. So let's get over the "oh I disagree with you so I can't think of anything nice to say" attitude. We're all supposed to be professionals. Let's act like it. (4/1/96)

\section{Teresa}

What I meant to say (sorry if I was unclear) is this:

I am not going to look the student in the eye and tell him "You're wrong." I'm not even going to think it. He has every right to think whatever he will. What he MUST do in my classroom is support his beliefs. Yeah, I wrote "Bill of Rights?" in the margin, and you might remember how Tim was saying that the student needs to anticipate the arguments that his audience may have, well, that's why I wrote "Bill of Rights?" If the student decides to THINK about opposing viewpoints, if he CARES ENOUGH to look into how others may think, or if he even bothers to logically think through his opinions, he may find things that could surprise him. Asking a student to think about opposing viewpoints, and especially to justify his OWN opinions is NOT telling him he is wrong. If he can logically explain his viewpoints, knowing what the arguments against him will be, he will strengthen his own opinions. (Something I see as good). Asking a student to anticipate other's questioning, and asking him to make some sense of his own opinions logically is in NO WAY "shoving my opinion down his throat."

You called me irresponsible. Well, sorry, but I think it is entirely irresponsible of ANY teacher, regardless of the subject matter, to not try to expand their student's minds. I REFUSE to pass on any student from my class who hasn't had exposure to something new. I DON'T mean saying "here is what you should think." I mean plopping all the possible opportunities down in front of the students and saying, "find yourself, find your place in the world, find out what you really think. If you only learn one new thing outside the subject matter, fine, that's one thing more you didn't know before." ...

Remember: "The hottest fires of hell are reserved for those, who, in times of moral crisis, retain their neutrality." (4/3/96)

One of the characteristics of these two postings that impressed us was the students' total engagement with their own interchange. We would argue that classes dealing with response to student texts seldom engage in so nuanced or extended a discussion in off-line contexts. Note that Michelle is saying that it's not enough to avoid disagreeing with students' points of view by responding with questions to students' arguments—writing teachers, she argues, must also refrain from conveying their disapproval by crafting their questions carefully and tactfully. This is the 
sort of sophisticated thinking that we often seek from students but seldom encounter. We hasten to add that such conversations do not accrue automatically to online environments anymore than they do to off-line environments. Pemberton's care in structuring the class-the training provided and the participation required-contributed to the students' feeling comfortable enough with the medium and with one another to dispute others' viewpoints with reasoned arguments. Later we will show some excerpts where this sort of engagement was more difficult to achieve.

Another of Pemberton's goals was to use ALN as a space where members of collaborative groups could stay in contact with one another, make arrangements for face-to-face meetings, and share information on their collaborative projects. Each group had a separate "space" on FirstClass with the option of making their conference area completely private or accessible to other members of the class. Though some groups made infrequent use of these conference areas, most groups used them not at all. Other, simpler technologies - such as the telephone-seemed more natural for keeping in touch and arranging meetings, while the regular three-times-a-week meetings in class provided ample opportunities for group members to exchange drafts and other reference materials. In this regard, then, ALN attempted to provide a service that was more easily provided elsewhere. The small-group conference areas became a "path of most resistance" with too many logistical hurdles to overcome for relatively minor benefits. As a consequence, they were largely ignored.

Finally, a special conference area was created for collaborative groups to post their completed projects-a detailed teaching plan for an instructional unit in English at the high school level. Groups were required to post these lesson plans two days before they were scheduled to present them in class, thereby giving other class members the opportunity (ideally) to look them over, think about them in advance, and ask pertinent questions after the presentations. Even though it seemed apparent that few other students in the class examined the lesson plans in advance (one of the features of FirstClass is that it can provide a list of the subscribers who have read a particular posting), quite a few more read and saved the posted plans in the days that followed. One of the things that was stressed often in the days leading up to in-class presentations was how valuable such lesson plans would prove to be to future teachers in the course who would soon, presumably, be teaching in state high schools. A number of students took this advice to heart and "stocked up" on the instructional units other groups created and wrote about.

In essence, then, two of the ways in which ALN was used in the Theory and Practice of Written Composition course were productive: out-of-class online discussions and central clearinghouses for useful information tied to course assignments. The third way ALN was used-as a contact site for members of collaborative groups-was remarkably unsuccessful because it violated the "natural" ease-of-use principles Pemberton had established initially for its implementation in the course.

\section{B. ALN in Electrical and Computing Engineering 270}

When we turn to an electrical and computing engineering course on circuit analysis, we are struck by how seamlessly the ALN component of the course fits with its professor's goals. Ostensibly Professor Burks Oakley set up the ALN component as a way of having students receive help in working out the weekly assignments for this introductory course. ECE 270 is essentially a sophomore engineering course that this particular semester had 350 students enrolled. The students completed network-based homework and quizzes over the weekly material and also posted any questions they had about the homework problems to the PacerForum conferencing system. Undergraduate teaching assistants, who had already taken the course, were available to help students with their questions until 11:00 p.m., and other students often helped each other with problems as well. In addition, we found that there were few times when Oakley himself wasn't available to answer questions and encourage his students. His immediate goal for the ALN-based 
course was to improve student learning through the use of immediate feedback and online help. At the end of the course, he also awarded students extra credit for independent projects they worked on and posted on PacerForum. Here is a sampling of the engineering course's postings:

Ian 1:09 AM

I was wondering if you could give me some help with finding the phase angle in active filter problems in general. The attached picture is just one example of a problem which has given me some trouble. Since I am getting the parameters right to meet the specification I am pretty sure that I have the mathematical relationship down. What is the best approach to finding the phase angle in when you have a negative sign.

It seems when I try a way that makes sense I am wrong.

In this problem for example why can't you find the angle by summing the angle from the RfC1s terms on top, which should be +90 , and the angle from the R1C1s +1 term on the bottom, which should be -45 degree with taking the - sign into consideration?

Burks Oakley 4:15 AM

Ian - Sorry for taking so long to respond.

For this circuit, the basic configuration is that of an inverting amplifier, so there must be a minus sign (-180_ phase shift) in the transfer function. At high frequencies (in the "passband" of this high-pass filter), the jw term in the numerator and the jw term in the denominator cancel (note that $1+\mathrm{jw}$ is approximately jw at high frequencies), so the high frequency phase is $-180 \_$. At low frequencies, way below the critical frequency, the term in the denominator is approximately 1 , but you still have the jw in the numerator (+90_) and the MINUS sign (-180_), so the low frequency phase is - $90 \_$. At the critical frequency, the $1 /(1+\mathrm{j} 1)$ term contributes an angle of $-45_{-}$, so the transfer function has an angle of -135 _ at the critical frequency.

Hope this helps.

From the dialogue included here, it becomes apparent that Oakley attributed much of the learning that took place in his course to the timeliness of his or the teaching assistants' responses. His tongue-in-cheek "sorry for taking so long to respond" reflects the satisfaction he derives from answering students' queries on a timely basis. Note also that in the above dialogue Ian posts the message well into the early hours of the morning and that Oakley, not so much a night owl as an early riser, responds barely three hours after the posting. And we hasten to note that in daytime hours the response time in Oakley's classes can usually be measured in minutes rather than hours. As we review the engineering class's postings, however, we are also struck by the thinking "aloud" that goes on and by the teamwork that also takes place as the circuit analysis solutions are reached. In other words, in good WAC fashion-by thoughtfully analyzing the specifics of the problem in writing - the students often come upon the answers they seek by thinking and talking (writing) it through with classmates. Consider, for example, the following exchange.

Jason 11:02 AM

I am having trouble trying to figure out how the current splits to go through the two capacitors $\mathrm{C} 1$ and the $80 \mathrm{uF}$ one. I do not know if we went over this in class but I do not think so.

I know that the voltage across those two cap. should be equal, but that is as far as I can get.

Ernest $12: 41 \mathrm{PM}$ 
I am having the same problem. I don't recall being taught how to do this??

Chris 12:49 PM

I'm thinking that if you know the voltage across the pair in parallel, there's no reason why you can't combine them into one capacitor, solve the problem just as you did for $\mathrm{C} 2$, and you've got your answer...

Anyone feel free to shoot me down if I've made a wrong assumption!

Dave 1:53 PM

Following Chris's advice, and checking signs VERY closely, I did somehow get the right answer. Play around with the numbers you get and test them. Then try to figure out why.

Jason 2:54 PM

I figured out that you can find the equivalent cap. and find the voltage across that equivalent cap. Chris was right though, you have to pay attention to the signs. Hope that helps.

It's also interesting to look at the differences in the kinds of discourse that characterize the postings of the humanities classes when compared to the engineering classes. Oakley especially was struck by how discursive the humanities students postings tended to be-how what he would consider "efficiency of prose" was often neglected in the humanities students' attempt to explain fully a particular point of view. The length of Pemberton's students' messages were several paragraphs, and Hawisher omitted paragraphs her students wrote in order for the paper to conform to the length expectations of the editors. We also found that not unlike our WAC experiences with faculty in other disciplines, the ALN experiments led us to compare our classes with those of our colleagues and to reflect on our own goals for discipline-specific classes. Sharing our teaching experiences across campus also had the unexpected result of encouraging dialogue among the various faculty as to what constituted appropriate ALN writing in the various classes.

\section{CRAFTING ONLINE ASSIGNMENTS}

As we mentioned earlier, faculty from a variety of disciplines incorporated learning networks into their writing-intensive classes. One of the problems that the faculty, especially in the humanities courses, faced related to how we might structure online assignments so that they elicited the kinds of thoughtful responses Michelle and Teresa demonstrate in Pemberton's classes. Clearly, students need to perceive the subject matter as meaningful, though the "meaning" it has for them can be constructed along any one of a variety of dimensions-personal, intellectual, academic, or professional, to name just a few. But even more importantly, students sometimes need to be encouraged explicitly_-given "permission" as it were-to use forms of discourse that go beyond the relatively narrow and confining conventions of academic prose when responding to specific assignments online. As we alluded earlier, students are strongly aware that their online interactions take place in an academic, and therefore evaluative, context. The pressure to produce online texts which mimic the standard forms of academic essays can, accordingly, be difficult to overcome.

\section{A. ALN in English 382}

One example of this phenomenon, an eventually-successful assignment that grew out of our online experiences and which Hawisher posted for the students in her Writing and Technology class, 
involved the use of the print magazine WIRED. The Writing and Technology class, English 382, is primarily a junior level class again aimed at students who are majoring in the teaching of English. Because of the technology component, however, several students signed up for the course who were not English majors but who nevertheless were planning to enter the teaching profession. For this reason, she tried to construct assignments which focused on teaching but not necessarily on English teaching. As stipulated below, for the assignment she wanted the students to work on their response while she was attending the 1995 Conference on College Composition and Communication. Specifically, the assignment asked students to analyze the usefulness of WIRED magazine for their teaching, but it was part of a larger general goal for the course which required students to think critically about the kinds of resources-online and print-that they would find appropriate for their teaching

\section{Gail Hawisher}

Today, in class, I'm going to give each of you a recent copy of WIRED Magazine. I'd like you to look it over, read some of the articles, and decide for whom the magazine seems intended and whether it has value for you ... and/or for your teaching.

I'd then like for you to decide how-if at all-you could use it in your classes for teaching. If you think you can, post here a teaching plan to be used in conjunction with an article, series of articles, pictures, advertisements, or some other aspect of the magazine. If you can't, please post an extended argument against its pedagogical utility, giving examples from the issue you have.

With a little bit of luck, I'll try to read some of your postings from my hotel room in Washington, D.C. If at all possible, post your assignment here on or before next Monday, the 27th. Thanks!

\section{$\underline{\text { Mark }}$}

To begin, I recently had an argument with a friend about the issue of presentation vs content. I argued that in today's technology driven world that presentation was as important as content. I said that a piece of writing could not rely solely on either aspect in order to be taken seriously. He contended that a paper should be judged on content alone.

The creators of WIRED would seem to take my side of the argument. Although at first it seemed that they focused more on layout and that almost turned me off in itself. But on a closer inspection the articles were well written and very informative to even a computer novice such as myself.

(two more paragraphs follow)

\section{Robert}

First of all, this magazine impressed me. It impressed me in terms of both the aspects that I assume hold constant across issues (format, type of articles) and the specific issues that this one issue brings up.

The one single thing that struck me most about this magazine was the prevalence and omnipresence of advertisements. I assume that this is a characteristic not unique to this issue. This is accentuated by the fact that a lot of the ads are hard to distinguish from the actual stories and articles. I think this is by design in a way. The magazine's designers seem to have a similar mindset in designing their magazine that advertisers do in designing ads. Catching the reader's eye, displaying something provocative, and getting readers to look twice are important goals. In a more conventional news magazine like Time or Newsweek, having catchy-looking stories is not a prime goal in designing. 
(four paragraphs follow)

This is getting way too long. So, in short, my teaching suggestion is to use the whole magazine, including the advertisements, if it is to be used at all. I would be uncomfortable copying an article and giving it to students, since it comes from a context that is so imbedded in corporate interests. I would encourage students to make connections among the stories, the format, and the advertisements.

\section{Gary}

The most efficient (and therefore perhaps the best) pedagogical classroom use I envision for this "Wired" magazine edition is found in its advertisements. (The articles are to some extent interesting. However, it would seem that one for the most part needs to wade too far past the quasiridiculous and "inefficiently" speculative, at least for class purposes.) As a result, I, again, see a much greater value (and more efficient use) in its advertisements.

(two paragraphs follow)

$\underline{\text { Carl }}$

Gary . . . . although I have no idea what you mean by quasi-ridiculous and inefficiently speculative, I would disagree that the articles are useless for classes. In fact, my issue contains several that I would consider using, such as "The Man Who Stole Michael Jackson's Face" about a guy who manipulated Michael's face onto a nude female body and got sued for stealing his image, which could lead into issues of intellectual property; "The Last Human Chess Master" which is about when computers are able to fully reproduce human activity. . .what then will distinguish between humans and computers? There are some others.

I thought I'd discuss the gender issues thing_—it just so happens that my issue contains a letter critiquing WIRED for its white-maleness. It goes like this:

Time to Walk the Walk:

I am becoming increasingly impatient with the decidedly boogie-white-male, "liberal" slant with which Wired approaches certain issues concerning information technology. Wired seems knee-deep in a kind of "white-male"-ness that is more of a consciousness than a statistical state of being determined by skin color of genitalia. In other words, I am not as concerned with the number of "actual" white males who occur in the mag either as writers or subjects, as I am with the specific nature of the content.

(three paragraphs omitted)

Anyway, does this issue touch of in anyone else's mag?

What we find interesting in these postings is that despite the instructor's intent to engage students in discussion while she's out of town, the assignment initially elicits almost the same type of postings that the earlier "summary" assignment elicited. Although the students don't write summaries, they seem to be posting in a vacuum with little sense of an audience other than the instructor, reproducing (somewhat more informally) the kinds of paper assignments they have traditionally completed over the years. And they do this in spite of the fact that they had been carrying on engaged online discussions throughout the semester. This was the first time, however, that the instructor gave them a specific assignment to respond to. Up until this assignment, they had been responding to in-class presentations and discussing online different kinds of computer applications with which they were experimenting in class along with discussing the various readings assigned for the course. 
Hawisher read these responses rather disheartenedly from Washington, D.C., and lamented having given the assignment until she encountered the fourth response. Here Carl responds, "Gary . . . although I have no idea what you mean by quasi-ridiculous and inefficiently speculative, I would disagree that the articles are useless for classes." Carl names the person he's addressing and begins to question Gary's assessment of WIRED's pedagogical utility. From this point on, the students began to respond to one another and often commented on another posting before setting forth their own evaluations.

$\underline{\text { Joan }}$

Did anyone else attend Andrew Ross' lecture on Friday (he's the head of the American Studies dept. at NYU)?

(three paragraphs omitted)

What struck me most about [WIRED] is its "maleness" for lack of a better term. By that I mean its ads and articles and fillers seem to be geared toward an audience that is cynical and irreverent about "traditional" values (career, marriage, family, the house in the suburbs). Kind of like Rolling Stone meets the Sharper Image catalog.

\section{$\underline{\text { Carl }}$}

Many (myself included) have criticized WIRED for its consistent "white male-ness"especially the advertisements. However, advertisers gear ads, obviously, towards their consumers. . .and I'd wager that they know exactly what the readership of WIRED is (majority male? Probably. Majority white? Probably.) and they gear their ads to that group of people. Are the advertisements in EBONY a problem because they target African-American readers? What do you think? How about Rolling Stone's ads that appeal to, generally, younger music listeners. At what point are the magazines biased and at what point are they just representative?

\section{$\underline{\text { Brian }}$}

After reading through several issues of "Wired", I have to agree with Carl and Joan that the magazine unquestionably targets white males. I would have to say, however, that it targets teenage white males. I think that part of the reason for the flashy ads is to display many of the new capabilities of desk top publishing. Where better to display cutting edge graphics then in a magazine that deals with cutting edge technology. I think part of there image also stems from their desire to target a younger audience. For those who have been raised on MTV and video games, this medium is not all that unfamiliar. Likewise, with the attention span of Americans dramatically declining due to the "clicker," a product almost needs flashy advertisements to ensure that their product will be seen.

(three paragraphs follow)

\section{Gail Hawisher}

Great observations here! And thanks for the joke, Joan :)) Let me add something I took off of Edupage, and we can use it to start our in-class discussion Monday.

\section{THE WIRED REVOLUTION}

While saluting Wired magazine's worthy premise as a publication that addresses the social and cultural effects of digital technologies, the director of the 21st Century Project at the University of Texas blasts Wired for its "fevered, adolescent consumerism, its proud display of empty thoughts from a parade of smoke-shoveling celebrity pundits, its smug 
disengagement from the thorny problems facing postindustrial societies, and most annoyingly, its over-the-top narcissism. If this is the revolution, do we really want to be part of it?" (New Republic 1/9-16/95 p.19)

What do you think? In many ways, I'm rather taken with WIRED for the sheer energy displayed. I did, however, have to laugh at Joan's observation that it seems to be a cross between the Sharper Image catalogue and Rolling Stones magazine. I wonder if it could be transformed into a magazine that suits more of us more of the time....

(two paragraphs follow)

Although Hawisher came to regard the assignment as effective (i.e., students not only made insightful observations about WIRED but also engaged in a written dialogue with one another), it's interesting that she never stipulated in the opening assignment that students should respond to one another and comment on one another's ideas. For her, with over ten years experience online, this sort of behavior was a given. We would like to think that the modeling of what she considered appropriate online response (e.g., the use of writers' names, a little bit of praise, a little bit of commentary, an idea offered, some questions) was a strategy to which students responded well and which they too tried to incorporate into their own online repertoire. Our tentative conclusion, however, is that students interpret online assignments as being not very different from the customary paper assignments they receive-especially when they have little experience with online writing. As we all learn in WAC workshops, good teaching involves letting students in on our expectations for them: we need to discuss with them beforehand what they-students and instructor-would regard as the successful completion of an assignment. This should not be new to any of us who work with WAC.

\section{B. A Shared Pedagogy}

Indeed, the more successful online assignments seemed to have much in common with the classroom practices that we frequently advocate in WAC seminars. Those faculty who emerged from their ALN experiences most satisfied with the results generally followed the classroom practices Toby Fulwiler recommended many years ago for writing assignments grounded in WAC theory. ${ }^{12}$ Among his recommendations, for example, those to which the faculty adhered most closely included the following:

- Prepare a context for each assignment. When students are asked to write about something related to the subject in your class, it's often possible to plant fertile ideas in advance that will help generate more comprehensive writing.

- Ask students to write about what they know, not what you already know. Where possible, make your assignments approximate real communication situations, where the writer/speaker communicates something to a reader/listener who wants to learn more about it.

- Use peer(s) . . . to motivate and educate each other.

- Integrate writing into the daily activity of your classroom. Effecting this generalized advice can actually have a profound effect on all the formal writing you require of your students. (27-29)

When instructors neglected to use these precepts as guidelines, invariably their and their students' online experiences were less satisfying than they would have liked. Not only was a great deal of advanced preparation necessary for the classes but, like all pedagogical innovations, ALN needed to be attended to on a daily basis with students needing subtle and not so subtle reminders from the instructor that the online context was every bit as important to learning as the class's face-to-face encounters. 


\section{ALN and WOW (the Writers' Online Workshop)}

Partially as a result of our largely successful implementation of ALN into WAC classes, we also decided to extend to the WAC classes the services of the Writers' Workshop, the drop-in and now online writing lab of the Center for Writing Studies. Because ALN was being used extensively by courses that were designated writing-intensive, it seemed fitting that the Writers' Workshop provide some significant support to the students in Sloan courses via ALN. As mentioned earlier, the Sloan Center gave us funding for two TAs in the Writers' Workshop who were specifically intended to provide online writing help to Sloan courses, with one TA assigned to courses using FirstClass and the other to courses using PacerForum.

From the beginning, there were important obstacles to confront and negotiate with the instructors of the online WAC courses. The first was the issue of permission. Not all WAC instructors wanted Workshop TAs to have access to their course discussion areas, and not all instructors wanted the Workshop conference folder to appear on their students' desktops. Several crucial weeks when writing assistance could have been provided to students were lost while administrative issues of this sort were being resolved.

The second obstacle to confront was one of icon placement. Where, exactly, should the conference icon for the Writers' Workshop appear? This was not a trivial question, as it turned out, and we discovered that the decisions we made about placement -- or those that were forced upon us for political and practical reasons -- were often the single most significant factor that determined the degree to which students availed themselves of online Workshop resources.

Both PacerForum and FirstClass (and many other online conferencing software packages) have hierarchical structures. That is, when users log in, they are presented with an opening "desktop" containing an assortment of icons that will each open new windows or discussion threads. When these new windows are opened, they generally overlay the desktop and obscure the icons beneath them, effectively removing the icons from immediate perception and easy access. Though it made sense initially to put the Workshop icon at the highest level where it could be seen whenever students logged in, what we subsequently found was that the icon was quickly covered by message windows early in each session and students soon forgot that the Workshop was available as an online resource for their writing. (See Figure 4.) We suspect that had the Workshop icon been placed at a level where it would be constantly visible-inside the course discussion area, for example - then students might have been more likely to make use of the Workshop online. The issue of visibility, then, emerged as an important one for us, and we would counsel other instructors to consider it as well when constructing their own ALN networks.

\section{A. Policies of Use and the Writers' Online Workshop (WOW)}

The third obstacle to address was what our policies of use should be. Because there were, when all administrative and permissions issues were resolved, approximately 700 students who would have access to the Writers' Workshop area via ALN, we felt it was important to set some relatively clear and somewhat restrictive policies for use that would explain to students what sorts of help they could expect via ALN and that would keep the two TAs assigned to monitor the Workshop's online areas from being overwhelmed with work. The policies we decided upon were similar to those which held in the walk-in Writers' Workshop: consultants would look at and provide feedback on drafts, but they would not be proofreaders or graders. Our preference was that students submit drafts with specific questions that they wanted to have answered, and in this way we hoped to head off the potential result that students would routinely send consultants their drafts without engaging in any sort of dialogue. We wanted students to reflect on their writing before submitting it and 
provide some guidance for the TA's response. Our hope was that the consultants could engage in the same sort of dialogic interaction online that characterized their interactions with students in face-to-face conferences. Our policies may inadvertently have discouraged students from accessing the Workshop. In retrospect it might have been a more effective policy to encourage all students in WAC classes to turn to us for help and then negotiate the terms under which we would advise them.

The Writers' Workshop's presence online was largely ignored by students, for reasons already alluded to, for reasons that should have been obvious in retrospect, and for reasons which were embodied in the very structure of the ALN course-specific discussion areas. Over the course of an entire semester, the Workshop TAs had only a handful of interactions with students, and most of those interactions consisted of only a single inquiry and response.

\section{B. Students' Neglect of the Writers' Online Workshop (WOW)}

The icon placement issue, as mentioned earlier, presented a significant difficulty for students. Most of their online work took place in the course discussion folders, and these folders, when opened, obscured the folders that lay underneath. Since the Writers' Workshop folder did not appear in the discussion folder devoted to the specific course the students were working in, they tended to forget about the Workshop as an online resource. Further, since most students logged into their ALN accounts to participate in class discussions or to get pertinent information from the course instructor (syllabi, assignments, or class notes), and since most of them used public sites on-campus to log in rather than doing so remotely from their home computers, they were generally not likely to have their written work with them on disk to send to the TAs in the Workshop.

A more obvious reason for the lack of student interaction with the Workshop online was the comparative ease with which the students could see Workshop TAs in the campus writing center. Most students at the University of Illinois either live on campus or close to it. Getting to the writing center poses few problems, and getting an appointment to talk with a Workshop TA is only a matter of making a simple phone call. Students knew that if they printed out a copy of their draft and brought it into Workshop they could get a full hour of detailed, tightly-focused, and fullyinteractive feedback on what they had written. Making a visit to the Writers' Workshop was not only easier than sending it a document online, but the rewards were much greater for the amount of time and effort invested. Given the resident student population at the $\mathrm{U}$ of $\mathrm{I}$, this phenomenon seems obvious in retrospect, though it was our hope that more students would have taken advantage of the Workshop's online presence while they were otherwise connected to ALN.

A third, and more telling source of interference with the Workshop's ability to provide online assistance, was the ease with which students could communicate with instructors and course TAs who were also regularly available on FirstClass and PacerForum. Students generally saw little value in asking Workshop TAs to review their paper drafts when the instructors and departmental TAs-those who would eventually assigning grades to the papers-were also available for the same type of review. One of the reasons why writing centers tend to be so often used by students is their routine availability; writing centers are generally open for many more hours than instructors are generally accessible during their office hours. ALN, however, tends to equalize this disparity. Now instructors can be reached and consulted at the students' convenience, while the Workshop TAs are— just the reverse-restricted in the speed with which they can respond to student writing.

\section{CONCLUDING COMMENTS}


In its efforts to use asynchronous learning environments effectively, the teaching profession faces many challenges. We have listed three recommendations here, all of them aimed at helping instructors reconsider their goals and approaches-rethinking what it means to teach and learn while developing critical perspectives on the ways the new technologies can and cannot abet learning. The recommendations we make are few in number, but they may help guide our thinking about ways in which WAC can inform higher education's use of ALN over the next several years.

- ALN should be integrated fully into the course in ways that students and instructors perceive as useful, but should not attempt to supplant modes of instruction that are already useful and effective. Summary writing is useful for helping students pull together material they glean from their reading; it is generally less useful as a piece of communication in a conference discussion.

- Students need to be made accountable for their participation in ALN. Mere instructor encouragement and good will are generally not enough to overcome the initial inertia most students experience when they take on what appears to be an extra burden. Online conference assignments should be represented in a class syllabus in a way that makes them as important to the course as paper assignments - if indeed the instructor regards them as such[13].

- We need to be sure that networked classes make use of the best and most current knowledge of writing across the curriculum pedagogy and of the knowledge we have gained about the use of computers and writing in theory and practice. Although there is a growing body of research available on online teaching there is much we can continue to learn from writing across the curriculum strategies. These include not only notions of shorter, more frequent writing assignments, but also prompt—and thoughtful—responses from instructors and students to online postings.

These recommendations have grown out of our experiences at a large research university with plentiful computer resources but also with difficult logistics in providing computer training for students and faculty members. At other smaller campuses, the problems encountered in instituting online teaching will be different. But we are heartened by our experiences with WAC and learning networks over the past few years and will continue to refine our approaches for the online component of the Writers' Workshop (e.g., Harris and Pemberton)[14]. Indeed, we believe that bringing together WAC and ALN, in the hands of good teachers and with an adequate technological infrastructure in place, can contribute to an improved culture of teaching on college campuses. If we use electronic contexts wisely-if we recognize that they are not likely to reduce the amount of work or teaching on the part of instructors but that they can improve the quantity and perhaps quality of students and instructors' interactions-we may well be able to use learning networks to extend and improve upon what more than two decades of WAC have taught us[15].

\section{REFERENCES}

1. Russell, David. Writing in the Academic Disciplines, 1870-1990: A Curricular History. Carbondale, IL: Southern Illinois University Press, 1991.

2. Young, Art and Fulwiler, Toby (Eds.), Writing Across the Disciplines: Research Into Practice. Portsmouth, NH: Boynton/Cook, 1986. 
3. Herrington, Anne and Moran Charles (Eds.), Writing, Teaching, and Learning in the Disciplines. New York: Modern Language Association, 1992.

4. Hawisher, Gail E., and Paul LeBlanc, Charles Moran, and Cynthia L. Selfe. Computers and the Teaching of Writing in American Higher Education, 1979-1994: A History. Norwood: Ablex, 1996.

5. Frank Mayadas of the Sloan Foundation coined the term Asynchronous Learning Networks (ALN) to denote educational contexts in which learning is made possible through current, affordable technology. According to Mayadas, "Remote resources in this context can mean other people: students learn from their peers and also from experts such as tutors or faculty. Remote resources can also include more static resources such as library or software-generated simulations, access to laboratories at a distance or access to the work product of several remote collaborators, such as a jointly-created database, or a report. Asynchronous means that access to any remote resource is at the student's convenience, "on demand", so to speak. Asynchronous access is made possible mainly by advances in computer and communications technologies. A student, for example, can contact a colleague or a teacher through e-mail, or engage in discussion with a group through a conferencing system or bulletin board; he/she may participate interactively in a team project with other students that requires problem analysis, discussion, spreadsheet analysis or report-preparation through a modern commercial groupware package." See http://www.sloan.org/education/aln.new.html.

6. Blumenstyk, Goldie. Western States Continue to Plan Virtual College. Chronicle of Higher Education. June 14, 1996. A30-31. Honan, William H. "Professors Battling Television Technology," The New York Times, Tuesday, April 4, 1995. Section A: p. 8.

7. Mayadas, Frank. http://w3.scale.uiuc.edu/scale/

8. Prior, Paul, Hawisher, Gail E., Gruber, Sibylle and MacLaughlin, Nicole. Research and WAC Evaluation: An In-progress Reflection. WAC and Program Assessment: Diverse Methods of Evaluating Writing Across the Curriculum Programs. Kathleen Yancey and Brian Huot, eds. Norwood, NJ: Ablex, 1997.

9. PacerForum and FirstClass, both conferencing programs that allow asynchronous and nearsynchronous interactions among participants, were used in each of the classes described here as a supplement to regular class activities. The three instructors set up individual forums that corresponded to the structure of their courses. The writing technologies class, for example, participated in forums based on in-class student presentations and in other conferences titled teaching practices, gender and technology, reports on listserv discussions and many more. Both PacerForum and FirstClass are icon driven, with students clicking on the appropriate conference icon to join in class discussions. More information about the programs themselves is available from AGE Logic, 12651 High Bluff Drive, San Diego, CA 92130 for PacerForum and from Softarc Incorporated for FirstClass.

10. Eldred, Janet. Pedagogy in the Computer-Networked Classroom. Computers and Composition. 8 (1991): 47-61.

11. Students' names used throughout the paper are pseudonyms.

12. Fulwiler, Toby. The Argument for Writing Across the Curriculum. Writing Across the Disciplines: Research Into Practice. Ed. Art Young and Toby Fulwiler. Portsmouth: Boynton/Cook, 1986. 21-32.

13. Eldred, Janet Carey and Fortune, Ron. Exploring the Implications of Metaphors for Computer Networks and Hypermedia. Re-Imagining Computers and Composition: Teaching and Research in the Virtual Age. Eds. Gail E. Hawisher and Paul LeBlanc. Portsmouth, NH: Boynton/Cook, 1992. 5873. 
14. Harris, Muriel, and Pemberton, Michael. Online Writing Labs (OWLS): A Taxonomy of Options and Issues. Computers and Composition. 12.2 (1995): 145-60.

15. This paper was first accepted as a chapter for Donna Reiss, Richard Selfe, and Art Young's Electronic Communication Across the Curriculum to be published by the National Council of Teachers of English.

\section{Technology Endnote}

\section{URLs to be consulted in conjunction with this paper:}
ALN
http://w3.scale.uiuc.edu/scale/
Center for Writing Studies
http://www.english.uiuc.edu/cws/index.html
Writers' Workshop
http://www.english.uiuc.edu/cws/wworkshop/writer.html

\section{Listservs to be consulted}

WAC-L To join the writing across the curriculum list, send the following one-line message to listserv@ postoffice.cso.uiuc.edu: subscribe WAC-L firstname lastname

CCAC-L To join the computer-supported communication across the curriculum, send the following one-line message to listserv@VCCSCENT.bitnet: subscribe CCAC-L firstname lastname

\section{Hardware and Software:}

Students accessed Macintoshes and IBMs at the University of Illinois's CSO sites. PACERFORUM works primarily with Macintoshes, but a windows version of the program is currently being beta-tested. FIRSTCLASS works on both Macintosh and Windows platforms. See the Works Cited section for more information about the software packages.

\section{Biographies}

Gail E. Hawisher is Professor of English and Director of the Center for Writing Studies at the University of Illinois, Urbana-Champaign.

Her published work includes the co-edited collections, Critical Perspectives on Computers and Composition Instruction, On Literacy and its Teaching, Evolving Perspectives on Computers and Composition Studies: Questions for the 1990s, and Re-Imagining Computers and Composition: Teaching and Research in the Virtual Age. She has published widely in composition studies, and her work has appeared in such journals as Research in the Teaching of English, College English, Written Communication, College Composition and Communication, and the English Journal, among others. With Cynthia Selfe, she also edits Computers and Composition, an international journal devoted to examining issues related to writing, the teaching of writing, and the new technologies. Her most recent completed projects are the co-authored 
"Women on the Networks: Searching for E-Spaces of Their Own" and Computers and the Teaching of Writing in American Higher Education, 1979-1994: A History. Cynthia Selfe's and her college reader, Literacy, Technology, and Society: Confronting the Issues, has just been published by Prentice Hall.

Michael A. Pemberton is Assistant Professor of English and Associate Director of the Center for Writing Studies at the University of Illinois, Urbana-Champaign, where he also serves as Director of the Writers' Workshop (the campus writing center), and the Director of Outreach Programs.

He has published articles in College Composition and Communication, The Writing Instructor, Research and Teaching in Developmental Education, the Writing Lab Newsletter, Computers and Composition and the Writing Center Journal. In addition to being a founding co-editor of the journal Language and Learning Across the Disciplines, he is also the editor of the IATE Bulletin and Treasurer of the National Writing Centers Association. His regular column on "Writing Center Ethics" in the Writing Lab Newsletter was awarded the Outstanding Scholarship Award from the National Writing Center Association in 1994. He is currently preparing two books for publication-The Ethics of Writing Instruction: Issues in Theory and Practice (forthcoming from Ablex), and Writing Center Ethics: Contexts and Cases. 